\title{
METHOD
}

\section{High resolution magnetic resonance imaging of the anal sphincter using an internal coil}

\author{
N M deSouza, W A Kmiot, R Puni, A S Hall, M Burl, C I Bartram, G M Bydder
}

\begin{abstract}
An internal receiver coil was used to obtain high resolution transverse and oblique coronal magnetic resonance images of the anal sphincter in five normal volunteers and five patients. The internal sphincter had a high signal intensity on $T_{1}$ weighted, $T_{2}$ weighted, and STIR sequences whereas the conjoined longitudinal muscle and external sphincter had a low signal intensity. The internal sphincter (but not the external sphincter) showed contrast enhancement after administration of intravenous gadopentetate dimeglumine. The oblique coronal plane was particularly useful for showing the thickness and the relations of the external sphincter. Sphincteric abscesses as well as muscle defects, hypertrophy, and atrophy were clearly shown. The coil was well tolerated by most subjects. It has considerable potential for improving the diagnosis of anorectal disease.
\end{abstract}

(Gut 1995; 37: 284-287)

Keywords: anal sphincter, magnetic resonance imaging, endoanal coil.

The Robert Steiner Magnetic Resonance Unit, Department of Radiology, Royal Postgraduate Medical School, London N M deSouza R Puni

G M Bydder

Department of Surgery, Royal Postgraduate Medical School, London

W A Kmiot

Hirst Research Centre, Elstree Way,

Borehamwood

A S Hall

M Burl

Department of

Radiology, St Mark's Hospital, City Road, London

C I Bartram

Correspondence to: Mr W A Kmiot, Departmen of Surgery, Royal Postgraduate Medical School, Hammersmith Chool, Hammersmith London W12 OHS.

Accepted for rapid communication 29 March 1995 imaging (MRI) when a whole body receiver coi is used. ${ }^{3}$ The quality of magnetic resonance images may be improved by the use of a receiver coil placed in close proximity to the region of interest. We therefore constructed a dedicated insertable coil for MRI of the anal sphincter and assessed its value in a pilot study of 10 subjects.

\section{Methods}

This study was approved by the research ethics committee of the Royal Postgraduate Medical

Relative signal intensities with different pulse sequences
School. Five adult volunteers (three male and two female, aged 31 to 68 years; median 49 years) were imaged. All volunteers were free of anorectal symptoms and had normal anal sphincter resting and squeeze tone on rectal examination. Five patients (three male and two female, aged 26 to 77 years, median 47 ) were also imaged. Two of these patients presented with purulent anal discharge due to fistula in ano, one with difficult defecation because of anal stenosis, and two with faecal incontinence (one because of sphincter disruption after obstetric trauma and the other idiopathic).

Nine subjects were examined in the supine position. The lateral decubitus position was used for the patient with anal stenosis who could not lie supine. A cylindrical receiver coil $75 \mathrm{~mm}$ long and $9 \mathrm{~mm}$ in diameter was covered with a condom, placed within the anal canal and supported by an adjustable stand. Imaging was performed on either a 0.5 Tesla (T) Picker Asset or a 1.0 T Picker HPQ Vista MR scanner. Mildly $\mathrm{T}_{1}$ weighted spin echo (SE 780/20 msec (TR/TE)), $\mathrm{T}_{2}$ weighted spin echo (SE 2500/80 msec (TR/TE)), and STIR (short inversion time (TI) inversion recovery, IR 2500/30/110 (TR/TE/TI)) sequences were used. Transverse (perpendicular to the coil long axis) and oblique coronal (parallel to the coil long axis) $3 \mathrm{~mm}$ contiguous slices were obtained with a $192 \times$ 256 matrix and two to four signal acquisitions A $10-12 \mathrm{~cm}$ field of view was used. Intravenous gadopentetate dimeglumine (GadoliniumDTPA, $0.1 \mathrm{mmol} / \mathrm{kg}$ body weight) was given to one patient with anal discharge due to fistula in ano and another with liquid faecal incontinence.

\section{Results}

High resolution images of the anal sphincter were obtained in all subjects. The tissue signal was highest adjacent to the coil and decreased with distance from it. The useful imaging region extended at least $5 \mathrm{~cm}$ out from the centre of the coil in a plane transverse to the coil and included all components of the

\begin{tabular}{|c|c|c|c|c|c|c|}
\hline Sequence & Submucosa & $\begin{array}{l}\text { Musculus } \\
\text { submucosae } \\
\text { ali }\end{array}$ & $\begin{array}{l}\text { Anterior } \\
\text { submucosal } \\
\text { veins }\end{array}$ & $\begin{array}{l}\text { Internal } \\
\text { sphincter }\end{array}$ & $\begin{array}{l}\text { Conjoined } \\
\text { longitudinal } \\
\text { muscle }\end{array}$ & $\begin{array}{l}\text { External } \\
\text { sphincter and } \\
\text { levator ali }\end{array}$ \\
\hline $\begin{array}{l}T_{1} \text { weighted spin echo } \\
T_{1} \text { weighted spin echo with contrast } \\
T_{2} \text { weighted spin echo } \\
\text { STIR }\end{array}$ & $\begin{array}{l}\text { Very high } \\
\text { Very high } \\
\text { Very high } \\
\text { Very high }\end{array}$ & $\begin{array}{l}\text { Moderate } \\
\text { Moderate } \\
\text { Moderate } \\
\text { Moderate }\end{array}$ & $\begin{array}{l}\text { Low } \\
\text { High } \\
\text { High } \\
\text { High }\end{array}$ & $\begin{array}{l}\text { Intermediate } \\
\text { Very high } \\
\text { High } \\
\text { High }\end{array}$ & $\begin{array}{l}\text { Low } \\
\text { Low } \\
\text { Low } \\
\text { Low }\end{array}$ & $\begin{array}{l}\text { Low } \\
\text { Low } \\
\text { Low } \\
\text { Low }\end{array}$ \\
\hline
\end{tabular}



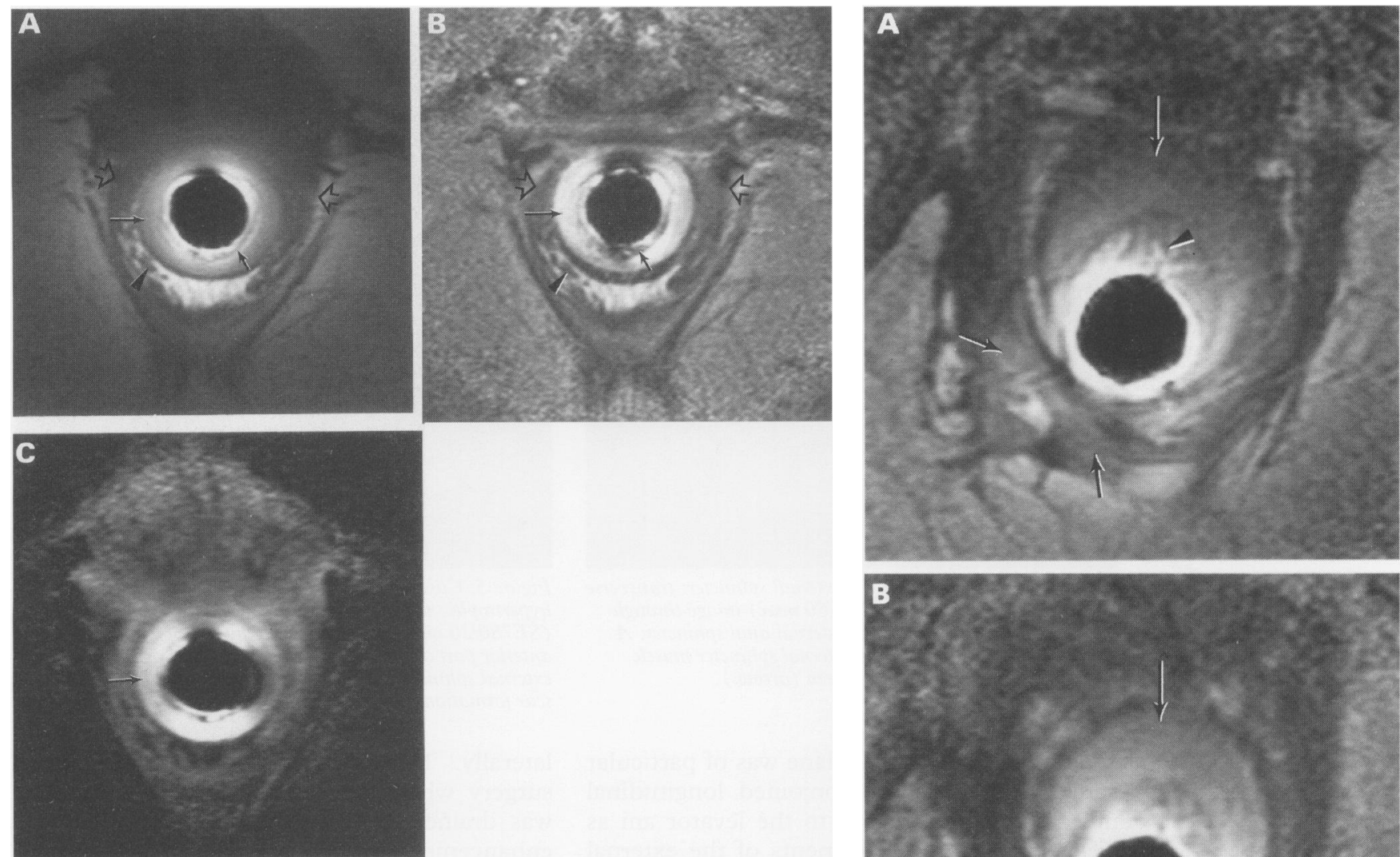

Figure 1: Normal subject: transverse mildly $T_{1}$ weighted spin echo (SE780/20 msec) (A), $T_{2}$ weighted spin echo (SE2500/80 msec) (B), and STIR (IR 2500/30/110 msec) (C) images through the mid-section of the anal sphincter in a normal volunteer. (Anterior is upper and posterior is lower in this and subsequent transverse Figures.) The high signal submucosa and adjacent low signal musculus submucosae ani (short arrow) are readily identified in $(A)$ and $(B)$. The internal sphincter (long arrows) has intermediate signal intensity on mild $T_{1}$ weighting and high signal on $T_{2}$ weighting and STIR sequences apart from a narrow low posterior signal rim. The longitudinal muscle (arrowhead) and the external sphincter (open arrows) are low signal on all sequences. The anterior low signal region seen at 12 o'clock on all sequences in an artefact from the coil.

sphincter complex in each case. Oblique coronal scans showed anatomical detail from the anal verge to the junction of the external sphincter with the levator ani and frequently beyond. The image quality was generally better

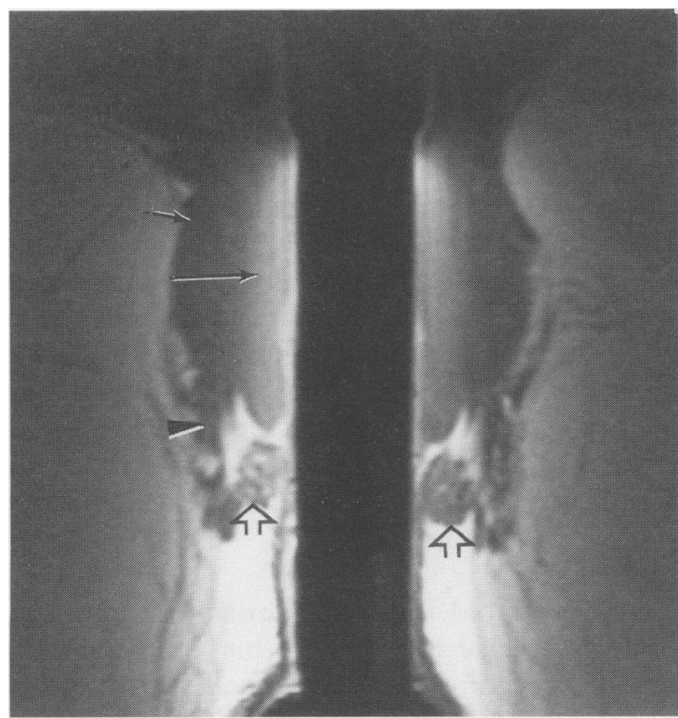

Figure 2: Normal subject: oblique coronal mildly $T_{1}$ weighted spin echo (SE780/20 msec) image through the anal sphincter of a normal volunteer (upper is proximal and lower is distal on this and subsequent coronal Figures). The internal sphincter (long arrow) has a homogeneous appearance. The subcutaneous (open arrows), superficial (arrowhead) and deep (short arrow) components of the external sphincter are well shown.

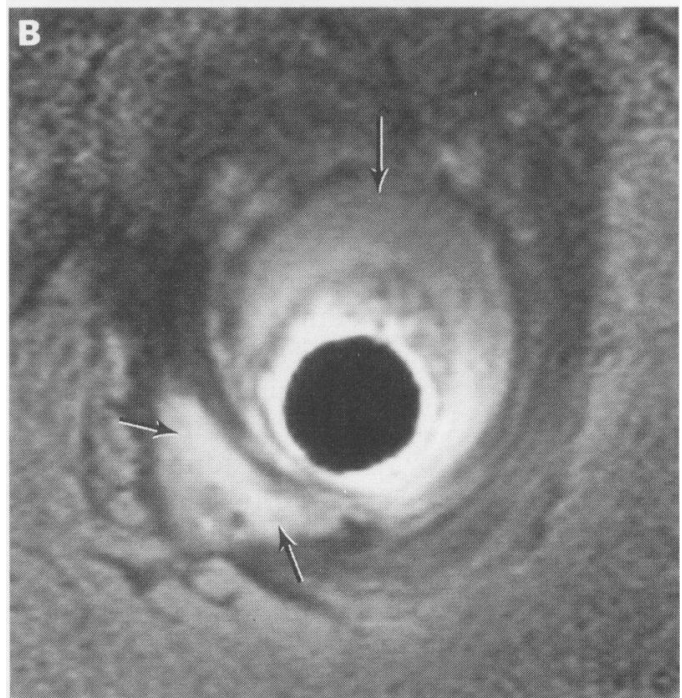

Figure 3: Case 1: fistula in ano: transverse mildly $T_{1}$ weighted spin echo (SE780/20 msec) images in a patient with idiopathic fistula in ano before $(A)$ and after $(B)$ administration of intravenous gadolinium-DTPA.

Disruption of the fibres of the external sphincter is seen centred around seven o'clock. There is an enhancing intrasphincteric abscess (short arrows). The internal sphincter (long arrows) also enhances following

gadolinium-DTPA and becomes higher signal than the musculus submucosae ani in (B). The anterior submucosal veins are seen within the submucosal layer in $(A)$ (arrowhead).

at $1.0 \mathrm{~T}$ but was also of good quality at $0.5 \mathrm{~T}$.

Striking differences in signal intensity were seen with the use of different pulse sequences. The Table summarises the signal intensities of the different components of the anal sphincter and its associated layers. The bulk of the internal sphincter was of intermediate signal intensity on mild $T_{1}$ weighting and high signal intensity on $T_{2}$ weighted and STIR images. It had a small peripheral lower signal rim present on $T_{1}$ and $T_{2}$ weighted spin echo images in some cases. The conjoined longitudinal muscle and external sphincter had a low signal intensity (Fig 1).

In addition to the major components, the musculus submucosae ani (subepithelial muscle) was shown as a low signal region within the high signal of the surrounding submucosa (Fig 1). The intersphincteric region had a high signal on $T_{1}$ weighted spin echo images consistent with the presence of fat. 


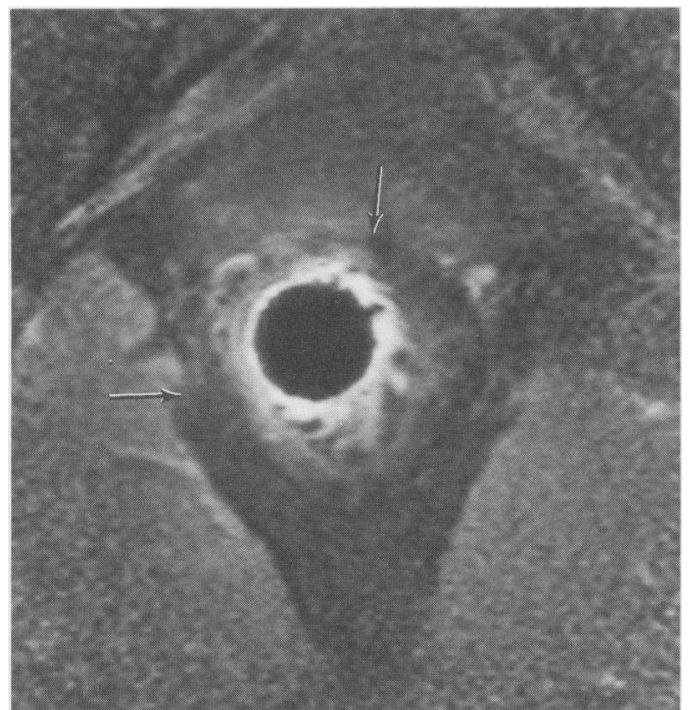

Figure 4: Case 3: defect in the external sphincter: transverse $\mathrm{T}_{2}$ weighted spin echo (SE2500/80 $\mathrm{msec}$ ) image through the anus above the level of the internal anal sphincter. $A$ defect in the deep fibres of the external sphincter muscle between nine and 12 o'clock is seen (arrows).

The oblique coronal plane was of particular value in showing the conjoined longitudinal muscle and its relations to the levator ani as well as the three components of the external sphincter (subcutaneous, superficial, and deep) (Fig 2).

On administration of gadolinium-DTPA the internal sphincter showed contrast enhancement in both cases in which it was used. This was regarded as a normal finding as it was uniform throughout the internal sphincter and was seen remote from sites of abnormality. Little or no contrast enhancement was seen in the normal external sphincter (Fig 3).

The high spatial resolution, differences in signal intensity between the internal and external sphincter, and availability of the oblique coronal plane were of considerable value in showing the different components of the normal anal sphincter as described in standard texts. ${ }^{4}$ Applicability of the coil to clinical problems was assessed in the five cases described.

Case 1 - perianal abscess and fistula in ano: a 50 year old man who had previously undergone a total of 23 sphincter explorations for persistent idiopathic fistula in ano presented with recurrent purulent discharge per rectum. Clinical examination was unremarkable. MRI showed an intrasphincteric abscess with a split in the fibres of the external sphincter at seven o'clock adjacent to an enhancing abscess. A fistulous track connected the abscess to the anal canal. This was confirmed at surgery where it was successfully treated (Fig 3 ).

Case 2 - fistulo in ano: a 31 year old man with a 20 year history of Crohn's disease and a defunctioning colostomy for the preceding two years presented with perianal discharge. On examination he had stigmata of perianal Crohn's disease with fistulas together with a clinical suspicion of an endoanal abscess. MRI of the anal sphincter showed an extrasphincteric collection on the right between six and 12 o'clock with the bulk of the collection placed

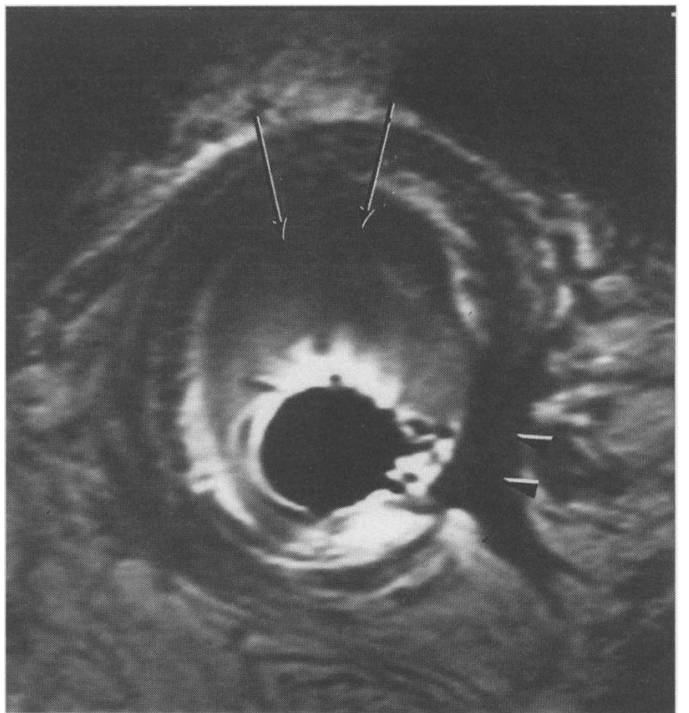

Figure 5: Case 4: anal stenosis with internal sphincter hypertrophy: transverse mildly $T_{1}$ weighted spin echo (SE780/20 msec) image showing hypertrophy of the anterior part of the internal sphincter (long arrows). The external sphincter is somewhat atrophic and distorted with scar formation (arrowheads) following the previous surgery.

laterally. These findings were confirmed at surgery when the extrasphincteric collection was drained. The internal sphincter showed enhancement after intravenous gadoliniumDTPA administration.

Case 3 - defect in the external sphincter: after an episiotomy one year earlier, a 26 year old woman suffered faecal incontinence and was treated with a defunctioning colostomy. The $\mathrm{T}_{2}$ weighted spin echo scans showed a large defect in the external anal sphincter between nine and 12 o'clock (Fig 4). The position and extent of this was confirmed at the time of surgical repair.

Case 4- anal stenosis and internal sphincter hypertrophy: a 77 year old man presented with a longstanding history of painful defecation over 20 years after a haemorrhoidectomy. After the initial surgery he had undergone several surgical procedures on the anal sphincter but still required regular anal dilatation before defecation. On physical examination there was evidence of anal stenosis. MRI showed a hypertrophied internal anal sphincter (maximum thickness $1.2 \mathrm{~cm}$ ) with a comparatively atrophic external sphincter (Fig 5).

Case 5 - external sphincter atrophy: a 54 year old nulliparous woman presented with a longstanding history of idiopathic faecal soiling. There was a history of straining to defecate but no relevant surgical history. On MRI an atrophic external sphincter was found (Fig 6). The internal sphincter seemed normal.

\section{Discussion}

In this study excellent image quality was obtained with the use of the internal anal coil both at $0.5 \mathrm{~T}$ and $1.0 \mathrm{~T}$. The sensitive region of the coil was well suited to the dimensions of the anal sphincter and extended beyond the region normally visualised with endorectal ultrasound. The increased spatial resolution was accompanied by a marked difference in signal intensity between the internal and 

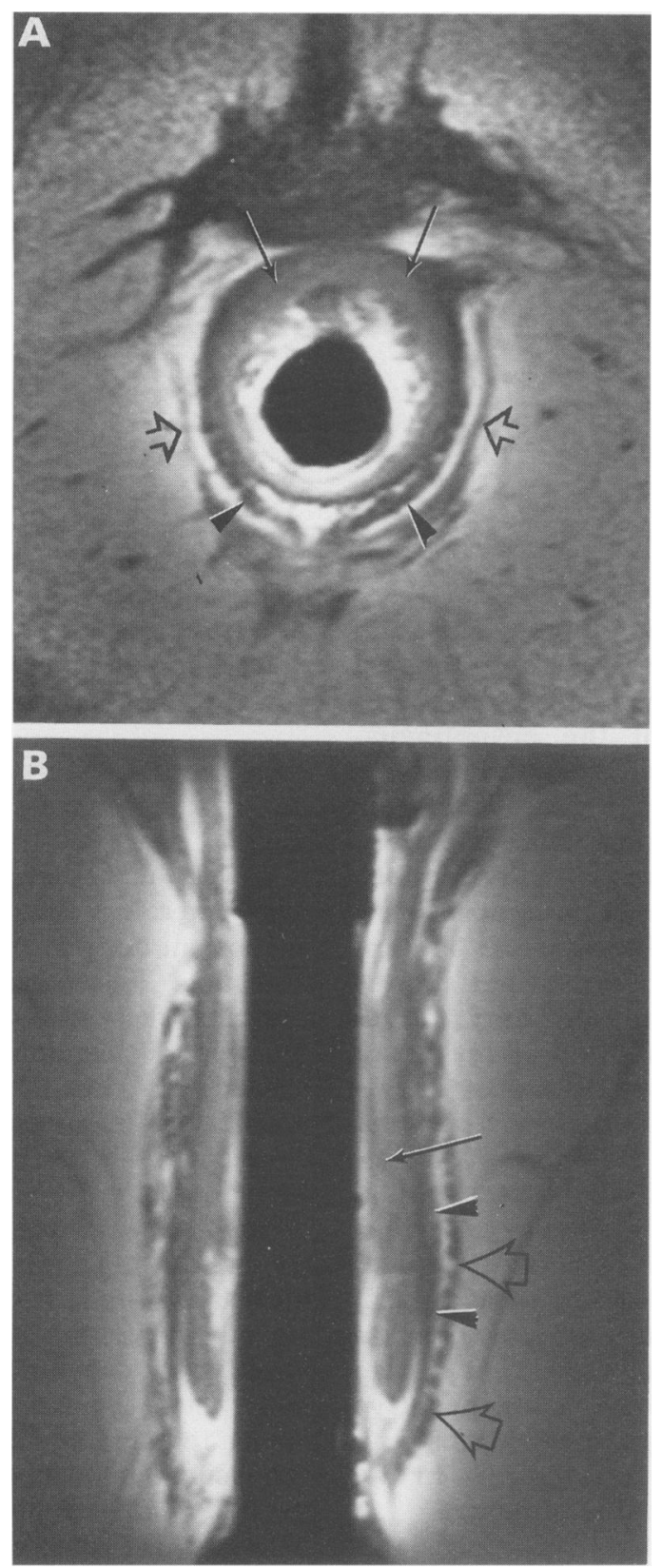

Figure 6: Case 5: external sphincter atrophy: transverse mildly $T_{1}$ weighted spin echo (SE780/20 msec) (A) and oblique coronal $(B)$ images in a patient with longstanding faecal incontinence. Pronounced atrophy of the external sphincter is seen (open arrows). The longitudinal muscle (arrowheads) is well seen and the internal sphincter (long arrows) is probably normal.

external anal sphincter and high sensitivity to disease. These findings have only been published previously in abstract form. ${ }^{67}$

The precise reason for the difference in signal intensity between the internal and external sphincters on all sequences is not known. Close proximity to the surface coil increases the signal from the internal sphincter relative to the external sphincter. The appearances with different sequences are consistent with the internal sphincter having a similar or shorter $T_{1}$ but a longer $T_{2}$ than the external sphincter. The internal sphincter consists of smooth muscle compared with the striated muscle of the external sphincter and it maintains an active tone. It is known from endoanal ultrasound that the internal sphincter is hypoechoic compared with the external sphincter.
It is not clear exactly why the internal sphincter shows contrast enhancement after intravenous gadolinium-DTPA administration. Contrast enhancement is normally associated with high tissue vascularity, high permeability of capillaries, and increased metabolic or physical activity. Any one of these factors either individually or in combination could be responsible.

Unlike the situation with ultrasound, the oblique coronal plane can be readily visualised with MRI and is of particular value in showing the components of the external sphincter and its relations to the surrounding muscles and other structures.

In general MRI has a high sensitivity to soft tissue abnormality. Infection and fluid collections are associated with an increase in $T_{1}$ and $\mathrm{T}_{2}$ while established scars usually show a reduction in $T_{1}$ and $T_{2}$. As a result with $T_{2}$ weighted sequences abscesses appear high signal and scar has low signal intensity. The cases in this study show that this high sensitivity applies to tissue abnormality in anal disease. Anatomical changes associated with hypertrophy and atrophy were also readily shown.

The use of an anal coil causes discomfort but was acceptable and well tolerated in nine of 10 subjects. The patient with anal stenosis experienced some pain during the examination but it was possible to scan him in the lateral decubitus position. Anal stenosis is a relative contraindication to the technique. Artefact from coil motion was satisfactorily controlled by the use of a clamp to maintain the coil position. The main disadvantages with MRI are the time required and the cost of an examination, which are both greater than for endorectal ultrasound.

To define the detailed anatomy of the sphincter and fully assess the clinical value of this technique, further studies will be necessary but it is already clear that the technique has considerable potential for improving diagnosis in disease of the anorectum.

We thank the Medical Research Council for their support.

Presented in part at the Progress in Magnetic Resonance meeting of the British Institute of Radiology, London, 3 October 1994.

1 Sultan AH, Kamm MA, Hudson CN, Nicholls JR, Bartram CI. Endosonography of the anal sphincters: normal anatomy and comparison with manometry. Clin Radiol anatomy and compa

2 Sultan AH, Nicholls RJ, Kamm MA, Hudson CN, Beynon J, Bartram CI. Anal endosonography and correlation with in vitro and in vivo anatomy. Br $\mathcal{F}$ Surg 1993; 80: 508-11.

3 Schafer A, Enck P, Furst G, Kahn T, Frieling T, Lubke HJ. Anatomy of the anal sphincters. Dis Colon Rectum 1994; 37: 777-81.

4 Netter FN. Rectum and anal canal, anorectal musculature. In: Oppenheimer $\mathrm{E}$, ed. The Ciba collection of medical illustrations. Vol III, part 2. Lower digestive tract. New York: Ciba, 1962: 57-63.

5 Williams PL, Warwick R, Dyson M, Bannister LH, eds. Gray's Anatomy. 37th ed. London: Churchill Livingstone, 1989: 1369-74.

6 Puni R, Hall AS, Coutts GA, deSouza NM. Development of an insertable surface coil for MRI of the anal sphincter. Proceedings of Progress in Magnetic Resonance. London: Proceedings of Progress in Magnetic
British Institute of Radiology, 1994.

7 British Institute of Radiology, 1994. Schouten WR, den Hollander JC, Lameris JS. MR imaging of the anal
Henten sphincter complex with an endoanal coil: normal anatomy and pathology. Exhibit at the Annual Meeting of the Radiological Society of North America Nov 27-Dec 2. Radiology 1994; 193 (P): 445. 